\title{
High-density culture of Vero cells in novel perfusion bioreactor system
}

\author{
Ravindra Patel, Debjani Dasgupta, Madhavi Vernekar* \\ School of Biotechnology and Bioinformatics, D. Y. Patil University, Navi Mumbai, India
}

\section{ARTICLE INFO}

Article history:

Received on: January 25, 2019

Accepted on: June 16, 2019

Available online: September 10, 2019

\section{Key words:}

SUBs, Vero cell culture, perfusion

bioprocessing, $3 D$ cell carriers,

non-woven polyester microfibers,

fixed-bed and packed-bed

bioreactors, $P L C$

\begin{abstract}
Improvements in upstream bioprocessing single-use systems have allowed implementation of high-density cultures in standard workflows. This study shows the capability of the novel designed single-use bioreactors to accommodates very high surface area per unit volume and enable the cell culture scientists to achieve and maintain a stable, high-density perfusion culture of Vero cells, without compromising mixing characteristics and nutritional homogeneity. Conventionally, adherent cell lines have been cultivated in non-controlled, labor-intensive, and space-demanding 2D surface technologies, i.e., roller bottles (RB) and multi-layer flasks. Fixed-bed and Packed-bed bioreactors are popular alternatives to culture high-density adherent cell lines for vaccines and other biologics production. However, the limitations that restricts the use of fixed-beds are nonhomogeneous cell seeding, huge mass transfer gradients, inability of maintaining nutritional homogeneity, limitation of bed size expansion and difficulties during scale-up of etc. In this study, we have shown the design and development of novel disc-based bioreactors in single-use format for high-density Vero cell culture. During the process run of 12 days, we have observed 4.97 population doublings and final cell density achieved was 0.438 million cells/sq.cm from the seeding density of 0.014 million cells $/ \mathrm{sq} . \mathrm{cm}$. Vero cell growth observed in novel bioreactor was significantly higher than the traditional culture devices, such as RB and multilayer flasks.
\end{abstract}

\section{INTRODUCTION}

Use of single-use cell cultivation devices in biopharmaceutical and vaccine industry has increased dramatically in last few years. These single-use bioreactor (SUB) technologies offer higher flexibility and modularity during production processes, ensured quality and safety to products, processes, and operators, significant cost reduction due to reduced CIP/SIP efforts and substantially lowered turnaround time $[1,2]$.

In today's market for bioprocessing of anchorage-dependent cell lines, number of adherent cell cultivation devices are being used with 2D or 3D support surfaces for cell attachment and growth [3]. Conventionally, adherent cell lines have been cultivated in non-controlled, labor-intensive, and space-demanding 2D surface technologies that is roller bottles (RB) and multi-layer flasks. Alternatively, micro-carrier technologies have been used

*Corresponding Author

Madhavi Vernekar, School of Biotechnology and Bioinformatics, D. Y.

Patil University, Navi Mumbai, India.

E-mail: madhavi.vernekar@dypatil.edu which allows reduction of footprint and coupled with automation increases the productivity of overall process output. However, lot of resources, time, experimentation, and cost is required to develop, finalize, and transfer an upstream process from conventional $2 \mathrm{D}$ surface supports to micro-carrier technology [4-6].

Fixed-bed and packed-bed reactor technologies which could solve many problems of 2D surface technologies were evolved over last two decades. These technologies are widely accepted and commercialised by many biopharmaceuticals and vaccine manufacturers. However, use of these bioreactors showed nonhomogeneous cell seeding, huge mass transfer gradients, inability in maintaining nutritional homogeneity, limitation of bed size expansion, and difficulties during scale-up which further limits its use [7].

Design concept and its geometrical aspects, surface area available for cell growth per unit, mixing and homogeneity criteria, and other important bioprocessing parameters of currently marketed adherent cell culture technologies ware tabulated and compared with the novel bioreactor system under evaluation study in Table 1 [8]. 
The lack of robust automation and industry demand for efficient and affordable SUBs to cultivate mammalian cells in adherent culture has triggered development of innovative technologies which not only debottleneck current issues but also add more value to the product and process output [9-11]. The novel designed bioreactor provides very large specific surface area per unit volume for cell attachment and growth. Along with large surface area, the novel bioreactor also ensures sufficient mixing and homogeneity within the culture geometry. Our ultimate aim is to develop a robust and affordable cell culture bioreactor system that meets the current demand of vaccine production industry.

Currently, cell culture-based vaccines are manufactured by using mammalian cell lines which includes Vero, MRC-5, HEK, and MDCK. Among various cell lines used in biopharmaceutical industry, Vero cells have been the most studied and thoroughly evaluated cell line used for vaccine production processes [12]. The Vero cell lineage was isolated from kidney epithelial cells extracted from an African green monkey which is continuous and aneuploid cell line. Vero is anchorage dependent cell line commonly used for production of vaccines, such as small pox and polio. Vero cells exhibit excellent growth characteristics on 2D and 3D surfaces which different surface treatment (i.e., Roller bottler, micro carriers, and packed bed bioreactor) $[13,14]$.

The present work involves designing and development of a novel bioreactor system for culturing adherent cell lines, such as Vero, $\mathrm{CHO}, \mathrm{HEK}$, and MDCK. Compared to commercially used cell culture devices, this novel bioreactor system can provide higher process efficiency with unmatched process automation and affordability.

\section{MATERIALS AND METHODS}

\subsection{Design and Construcion of Bioreactor}

The bioreactor developed has two parts, the process controller and SUB vessel which is a disposable vessel with working volume 51. During operation, volume of the entire bioreactor system includes volume of gas exchanger (GEX) attached to SUB and volume reaches to 6.51 . Before its use, the vessel was sterilized using gamma radiation at $25 \mathrm{KGy}$.

The rigid wall SUB vessel is made of injection molded cell culture grade, biocompatible Polyethylene terephthalate (PET) plastic material. Specially-treated cell carriers are sandwiched uniformly in parallel discs which construct the cell carrier bed. These cell carriers are made up of medical grade non-woven polyester PET microfibers. Magnetically coupled rotations of curved vanes in bioreactors ensure nutritional homogeneity throughout culture vessel geometry and achieves desired mixing time and mass transfer characteristics. Dual integrated aeration systems, i.e., purging gases in culture vessel through head space and through GEX, efficiently support gaseous requirements of the high-density cultures without sparging gases directly in culture medium (Fig. 1).

\subsection{Process Controller System}

Bioreactor process controller is easy-to-use system with capabilities of monitoring and control of parameters, such as temperature, $\mathrm{pH}$,

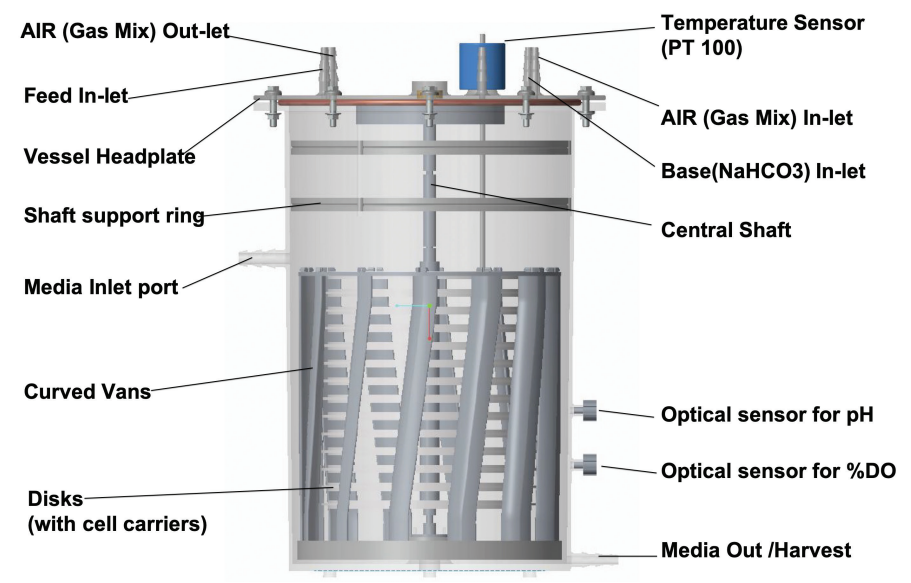

Figure 1: Culture vessel.

Table 1: Comparison of novel bioreactor system with other adherent cell culture devices.

\begin{tabular}{|c|c|c|c|c|c|c|}
\hline Performance criteria & RB & Multi-layer flasks & Hollow fiber bioreactors & Microcarriers (STRs) & $\begin{array}{l}\text { Packed bed } \\
\text { bioreactors }\end{array}$ & $\begin{array}{c}\text { Novel Bioreactor } \\
\text { system }\end{array}$ \\
\hline Culture type /technique & Static / 2D & Static / 2D & Partial dynamic/3D & Dynamic/3D & Partial dynamic/3D & $\begin{array}{c}\text { Dynamic / 3D } \\
\text { (segmented discs) }\end{array}$ \\
\hline Design concept & & 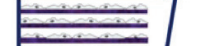 & $\Rightarrow \rightleftharpoons$ & & & \\
\hline $\begin{array}{l}\text { Surface Area (SA)/Unit } \\
\qquad\left(\mathrm{m}^{2}\right)\end{array}$ & 0.105 & 0.64 & 50 & 220 & 500 & 120 \\
\hline Culture volume (1) & 0.2 & 0.25 & 10 & 100 & 75 & 50 \\
\hline Mixing and homogeneity & + & + & ++ & +++ & ++ & +++ \\
\hline Ease of handling & No & Yes & Yes & No & No & Yes \\
\hline Operations & Manual & Manual & Automated & Automated & Automated & Automated \\
\hline Processing Cost & +++ & +++ & ++ & ++ & + & + \\
\hline
\end{tabular}


agitation, aeration, dissolved oxygen concentration ( $\% \mathrm{DO})$, gas flow rates (air, oxygen, and carbon dioxide), and pump flow rate for media and alkali addition (Fig. 2). Two non-invasive optical sensors for $\mathrm{pH}$ and $\% \mathrm{DO}$ measurement are inserted into the SUB vessel at the time of vessel construction. PT 100 temperature sensor is integrated in SUB for temperature measurement and control. Programmable logic controller based on Proportional, Integral, and derivative (PID) controller maintains temperature of the vessel through heating blanket/silicon heater. The bioreactor system is integrated with perfusion process. The controller system used is equipped with capacitance-based level sensor (to measure and control the level of culture media), peristaltic pumps for perfusion/media inlet, harvest, alkali addition, and media recirculation through GEX.

\subsection{Cells and Culture Media}

Vero cells (ATCC® CCL-81) adapted to DMEM: HF12 (1:1) media was used for this study. During seed development process, cells were cultured in DMEM:HF12 media prior to bioreactor inoculation. In bioreactor system, cells ware cultured in $1: 1$ mixture of DMEM and Ham's F12 media with 4 g/l glucose, 10\% FBS, and 1X Antibiotic-Antimycotic solution.

\subsection{Biorector Inoculation}

Vero cells were expanded to develop n-1 seed by multiple subcultures. Seed development was carried out in 5-layer T-flasks with 850 sq.cm surface area available per flask. Multiple seed flasks ware trypsinized to generate seed volume of $230 \mathrm{ml}$ with cell density of 12.6 million cells $/ \mathrm{ml}$. Protocol for Inoculation was embedded in the process control software and kept in auto mode

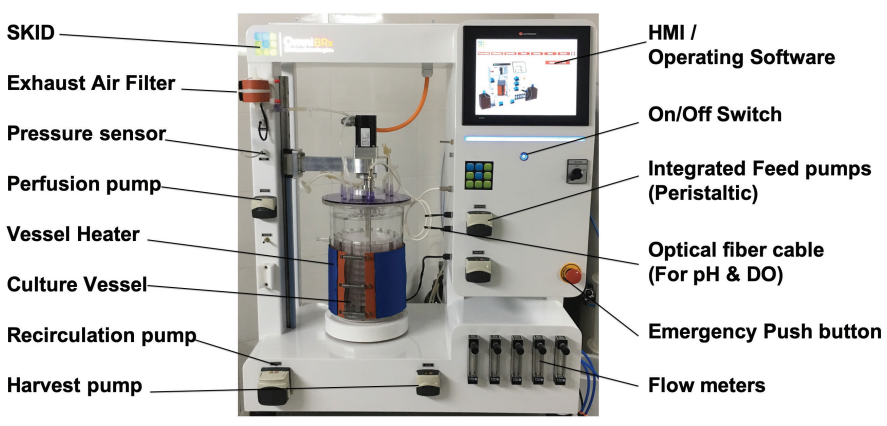

Figure 2: Control System \& Docking station for Culture vessel. for 30 minutes to promote quick and efficient cell attachment to treated surfaces of cell carriers. After the inoculation time elapsed, all the process controls were set in auto mode to control the process parameters at their set level.

\subsection{Batch Cultivation}

The available surface area for cell attachment and growth in each SUB vessel was 18 sq. $m$ and the corresponding volume in the bioreactor was 51 . Initial concentration of Vero cells after inoculation was targeted to 0.016 million cells $/ \mathrm{sq} . \mathrm{cm}$. The cultivation process of 12 days was studied with respect to cell growth, substrate uptake, and metabolite production. Bioreactor was sampled every 12 hours to access metabolic profile of culture. Dissolved Oxygen level of $35 \%$ air saturation was controlled by a gas-mix of air and oxygen using the advanced segmented controller with an aeration rate up to $0.15 \mathrm{lpm}$. $\mathrm{pH}$ was controlled at 7.0 by purging $\mathrm{CO} 2$ gas or addition of $0.5 \mathrm{M} \mathrm{NaHCO} 3$ via peristaltic pumps.

\subsection{Process Parameters Setup}

After a successful pressure leak test, culture vessel was filled with 5-1 culture media. Pre-calibrated single-use $\mathrm{pH}$ and DO sensors were pre- installed in the vessel. After the initial calibration, parameters were entered in the calibration screen, sensors were allowed to stabilized for 2 hours followed by sampling of media for $\mathrm{pH}$ recalibration (using offline $\mathrm{pH}$ measured). Culture media temperature was controlled at $37^{\circ} \mathrm{C}$. Curved vans rotation was set to $55 \mathrm{rpm}$, respectively, during cultivation process, corresponding to a mixing time of approximately 50 seconds (determined by visual color change method). Perfusion processing was carried out using $1 \mathrm{X}$ culture media with $10 \%$ FBS. Perfusion was started at $0.25 \mathrm{RV} /$ day (reactor volume per day) on day- 2 when glucose concentration declined. $20 \% \mathrm{w} / \mathrm{v}$ glucose stock solution was used to feed glucose as per the process need. Operating conditions and process parameters for the bioreactor processing are shown in Table 2 .

\section{RESULT AND DISCUSSION}

Glucose is the primary energy source for cell proliferation. Thus, glucose consumption rate can be directly correlated with cell growth. Lactate is by product of glucose metabolism and a secondary energy source for few cell lines. Lactate accumulation rate (LAR) and glucose uptake rate (GUR) represents the culture metabolism and growth kinetics. Since this was a perfusion culture system, lactate level expected to remain steady once

Table 2: Bioreactor process parameters.

\begin{tabular}{|c|c|c|c|}
\hline Sr. No & Parameter & Set point & Control means/Setpoint \\
\hline 1 & Temperature & $37^{\circ} \mathrm{C}$ & Heating blanket \\
\hline 2 & Agitation & $55 \mathrm{RPM}$ & Rotation of Vans \\
\hline 3 & $\mathrm{pH}$ & $7.1 \pm 0.1$ & $\begin{array}{l}\text { In Cascade to } \mathrm{CO} 2 \text { (for down regulation) and } 6 \% \text { sodium bicarbonate (for up } \\
\text { regulation) }\end{array}$ \\
\hline 4 & DO & $35 \%$ & O2 supply via GEX \& vessel overlay \\
\hline 5 & Inoculum density & 0.014 million cells $/ \mathrm{sq} . \mathrm{cm}$ & NA \\
\hline 6 & Operational Working volume & $6.5 \mathrm{~L}$ & NA \\
\hline 7 & Gassing strategy & Auto mode (PID) & $\begin{array}{c}\text { GEX: } 0.01 \text { LPM Air flow, } 0.01-0.2 \text { LPM O2 flow in DO cascade, } 0.01-0.2 \text { LPM } \\
\text { CO2 flow in pH cascade, Overlay: } 0.005 \text { LPM air flow. }\end{array}$ \\
\hline
\end{tabular}


it reaches to its tolerance level. Culture medium was sampled every 12 hours and the glucose and other metabolites levels ware measured. At the time of inoculation, glucose level was nearly $4 \mathrm{~g} / \mathrm{l}$ in and its consumption started at higher rate. As shown in Figure 3, average glucose concentration was maintained in the range of $1-4 \mathrm{~g} / 1$ and perfusion rate was set to $1.5 \mathrm{RV} /$ day during last few days of culture process. Lactate concentration in culture media was increasing with culture age in response to cell growth and glucose metabolism. The culture of Vero cells was successfully run for 12 days using perfusion mode. GUR and LAR was calculated for bioreactor culture, multi-layer flasks, and $\mathrm{RB}$ and shown, respectively, in the Figures 4 and 5. Continuous perfusion of nutrient-rich culture medium helped to maintain more consistent biochemical micro-environment around the cells by removal of spent medium and making available fresh nutrients to growing cells.

For cell density determination, multiple cell carrier discs were collected aseptically on day- 0 , day- 2 , day- 4 , day- 6 , day- 8 , and upon completion of perfusion culture (on Day-12) from carrier sampling port mounted over the head-plate of SUB vessel. The sampled cell carriers were treated with Trypan blue dye

Glucose conc. \& Perfusion Rate

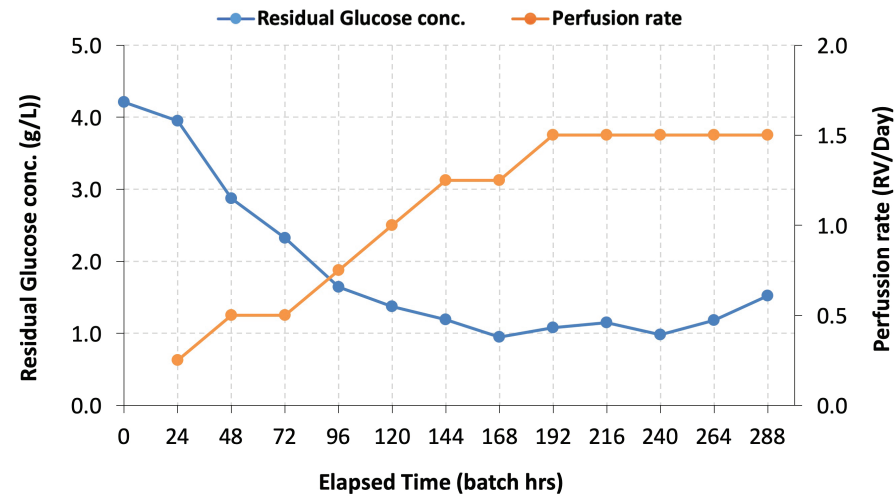

Figure 3: Residual Glucose Concentration and Perfusion rate trend.

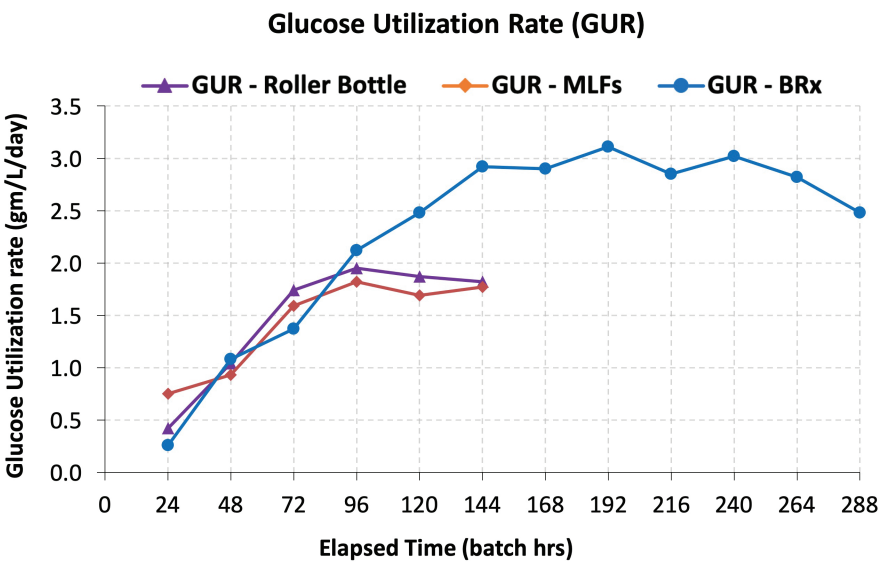

Figure 4: Glucose Consumption rate of bioreactor run compared with control devices. and crystal violet dye (CVD) reagent (nuclei counting method) to count the cells grown in each carrier discs. Culture process was initiated on day- 0 and actual cell density measured upon cell carrier sampling was 0.014 million cells/sq.cm (slightly lesser than calculated initial cell density of 0.016 million cells/ sq.cm) and highest cell density of 0.438 million cells/sq.cm was achieved on day-6. Cell growth achieved in RB and multi-layer flasks compared with novel bioreactor system is also shown in Figure 6. Cell density in RB and multi-layer flasks were 0.206 million cells/sq.cm and 0.190 million cells/sq.cm, respectively. Corresponding indirect cell density measurement was also carried out by trypsinization of selected cell carrier discs of the support matrix at the end of the batch and found in alignment of the cell number obtained. At day- 0 , the $\%$ viability of sampled cell carriers was observed to be $94.7 \%$. Cultures of multi-layer flasks and roller bottle was shown the \% viability of $95.4 \%$ and $96.1 \%$, respectively, at day- 0 . At the end of bioreactor process on day- 12 , the $\%$ viability measured was $89.8 \%$. On day- 6 , culture process of the multi-layer flasks and roller bottle was terminated and observed to show the culture viability of $91.8 \%$ and $93.3 \%$, respectively.

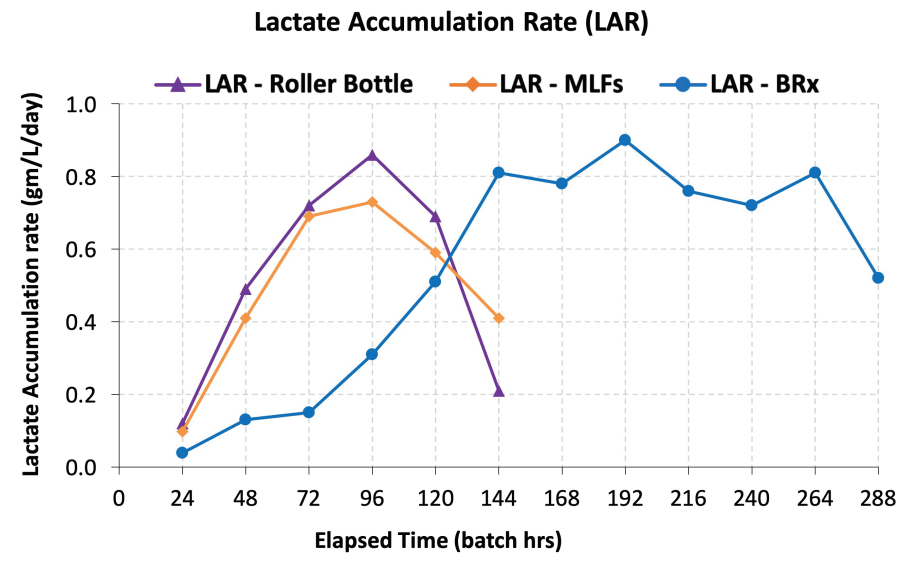

Figure 5: Lactate accumulation rate of bioreactor run compared with control devices.

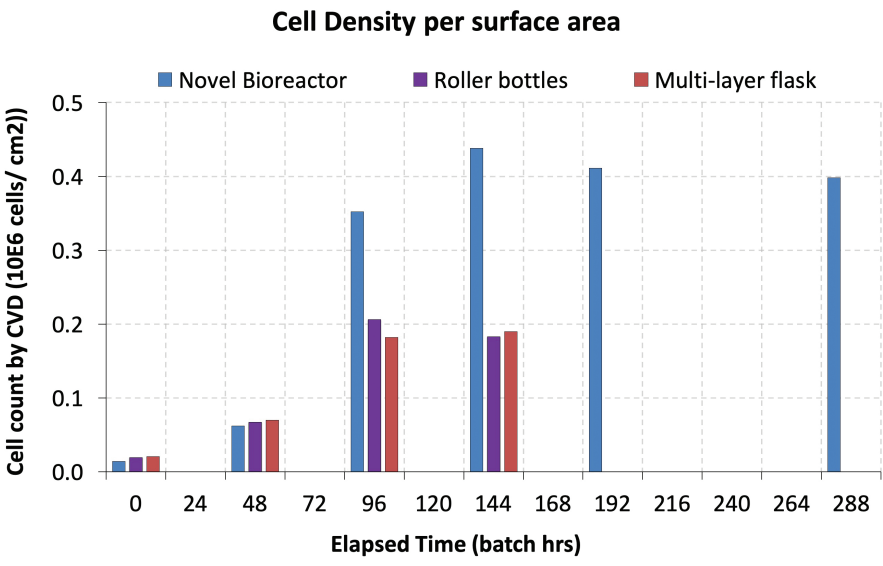

Figure 6: Cell density achieved per $\mathrm{cm}^{2}$ of surface area in culture devices. 


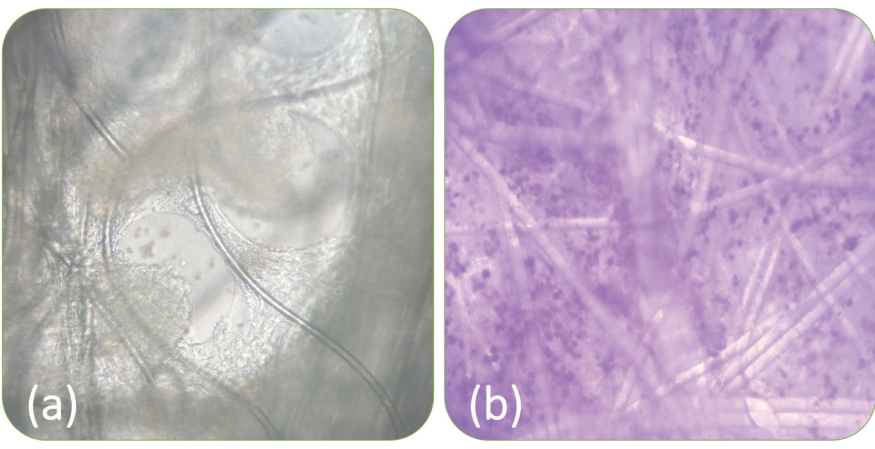

Figure 7: Vero cells growth on cell-carriers of bioreactor matrix (a) in phase contrast microscopy and (b) stained with CVD.

Typical 2D stationary culture devices, such as RB and multilayer flasks, can obtain two to three population doublings in 6 days of culture incubation. Under similar conditions, traditional bioreactors could achieve around four population doublings. The novel bioreactor under equivalent process conditions has achieved more than 4.5 population doublings of the Vero cells in 6 days, underlining its potential cell growth capabilities. Optimization of process conditions and growth media composition at industrial scale may result in achievement of even higher cell densities. Factors, such as initial cell seeding density, optimal cell seeding strategy for 3-D matrix and online monitoring of proliferation of cells, need to be explored further for achieving even higher cell densities.

The growth rate of Vero cells in this novel bioreactor was estimated to be faster than control 2D culture systems (i.e., RB and multilayer flasks) and require lower seeding density, it took 6 days to reach multiple fold increase of cell population. Culture parameters like $\mathrm{pH}, \% \mathrm{DO}$ and temperature was controlled at their desired set level throughout the batch.

At the end of culture process, cell carrier discs from top, middle, and bottom position were also collected and trypsinized to derive cell counts and \%viability. Each individual discs of the support matrix reached $0.41 \pm 0.06$ million cells/sq.cm, which can be translated to around 78.84billion cells/bioreactor. Images of Vero cells cultured on cell carrier 3D fiber matrix are shown in Figure 7. Figure 7a shows phase contrast microscopy of cell carrier where cells grown in the bioreactor 3D matrix can be seen within the vicinity of carrier fibres. Multi layered three dimensional growth of Vero cells was observed which indicate higher population doublings and cell density per square centimeter of surface area. Figure $7 \mathrm{~b}$ shows the nuclei of cultured cells stained dark violet using CVD.

\section{CONCLUSION}

Using the novel SUB, cell densities per square cm of surface area were found to be much higher than what is achieved in conventional cell culture technologies, such as cell factories, multiplate bioreactors, and RB. The twelve-day perfusion run has shown the partially exponential cell growth and delivered $\sim 4.97$ population doublings which can be translated to around 78 billion cells/bioreactor which is equivalent to $170 \mathrm{RB}$ (1,050 sq.cm surface area each).
When compared to commercial bioreactor systems of packed-bed or fixed-bed type, it is apparent that the cell growth observed in novel bioreactor system was comparable in terms of cell density achieved per sq. $\mathrm{cm}$. of surface area in bioreactor matrix. Packedbed bioreactors were reported to achieve 0.45 million cells $/ \mathrm{sq} . \mathrm{cm}$ on an average (reported in several publications) while the novel bioreactor system has achieved 0.41 million cells/sq.cm.

It can be very useful tool not just for production of biologics, vaccines but also for oncolytic viruses, cell and gene therapy commercialization and may evolve as potential platform to replace existing production technologies based on a case-bycase evaluation. Key parameters, like high cell density and high volumetric productivity along with other advantages of the bioreactor system like reduced foot print, truly scalable design of the bioreactor system, single use technology, no shear stress for cultured cells and automation with robust process controls its unique mixing capabilities and nutritional homogeneity characteristics will result in drastic reduction in manufacturing cost of the biologics products.

Due to its unique mixing capabilities and nutritional homogeneity characteristics, this novel perfusion bioreactor can achieve and maintain higher cell densities of Vero cells than any other cell culture system available in the market. With an advantages of perfusion mode bioprocessing, it significantly increases the volumetric productivity compared to current/traditional bioreactors.

\section{REFERENCES}

1. Shukla A, Gottschalk U. Single-use disposable technologies for biopharmaceutical manufacturing. Trends Biotechnol 2013; 31(3):147-54.

2. Eibl R, Kaiser S, Lombriser R, Eibi D. Disposable bioreactors: the current state-of-the-art and recommended applications in biotechnology. Appl Microbiol Biotechnol 2010; 86(1):41-9.

3. Kapałczyńska M, Kolenda T, Przybyła W, Zajączkowska M, Teresiak A, Filas V, et al. 2D and 3D cell cultures - a comparison of different types of cancer cell cultures. Arch Med Sci 2016; 14:1-10.

4. Ball P, Crawford B, Lindström K. 21 st century vaccine manufacturing BioProcess Int 2009; 4:18-28.

5. Wu F, Reddy K, Nadeau I, Gilly J, Terpening S, David J. Clanton, optimization of a MRC-5 cell culture process for the production of a smallpox vaccine. Cytotechnology 2005; 49:95-107.

6. William G. Whitford and Alain Fairbank. Considerations in scale-up of viral vaccine production. BioProcess Int 2011; 9(8):16-28.

7. Meuwly F, Loviat F, Ruffieux PA, Bernard AR, Kadouri A, von Stockar U. Oxygen supply for CHO cells immobilized on a packedbed of Fibra-Cel Disks. Biotechnol Bioeng 2006; 93(4):791-800.

8. Simón M. Bioreactor design for adherent cell culture- the Bolt-On Bioreactor Project, Part 1: volumetric productivity. BioProcess Int 2015; 13(1):28-33.

9. Pörtner R, Platas O, Fassnacht D, Nehring D, Czermak P, Märkl H. Fixed bed reactors for the cultivation of mammalian cells: design, performance and scale-up. Open Biotechnol J 2007; 1: 41-6.

10. Moncaubeig F. Simpler and more efficient viral vaccine manufacturing BioProcess Int 2013; 11(9):1-3.

11. Wang Y, Ouyang F. Bead-to-bead transfer of vero cells in microcarrier culture. Cytotechnology 1999; 31(3):221-4.

12. Meuwly F, Ruffieux A, Kadouri A, Stockar U. Packed-bed bioreactors for mammalian cell culture: bioprocess and biomedical applications. Biotechnol Adv 2007; 25(1):45-56. 
13. Rajendran R, Lingala R, Vuppu SK, Bandi BO, Manickam E, Macherla $\mathrm{SR}$. Assessment of packed bed bioreactor systems in the production of viral vaccines. AMB Express 2014; 4:25.

14. Barrett P, Mundt W, Kistner O, Howard M. Vero cell platform in vaccine production: moving towards cell culture-based viral vaccines. Expert Rev Vaccines 2009; 8(5):607-18.
How to cite this article:

Patel R, Dasgupta D, Vernekar M. High-density culture of Vero cells in novel perfusion bioreactor system. J Appl Biol Biotech 2019;7(05):50-55. 